\title{
Prevalence of dropout in measles immunization coverage among children in Kanyakumari District, Tamilnadu
}

\author{
M. Mathiarasu A. ${ }^{1}$, Anantha Raman V. V. ${ }^{2 *}$, M. Mathew A. ${ }^{3}$ \\ DOI: https://doi.org/10.17511/ijphr.2017.i1.05
}

${ }^{1}$ Alber M. Mathiarasu, Assistant Professor, Kanyakumari Government Medical College, Asaripallam, Tamil Nadu, India.

2* Anantha Raman V. V., MD, Associate Professor, Department of Community Medicine, SRM Medical College and Research Centre, Kanchipuram, Tamil Nadu, India.

3 Arumai M. Mathew, MSW, PGDCHM, Department of Community Medicine, SRM Medical College and Research Centre, Kanchipuram, Tamil Nadu, India.

Background: Measles is highly prevalent across globe and it is the main cause for childhood mortality and morbidity. It has now come down in developed countries that worked to prevent transmission. It is still continuing to be a widespread disease in developing countries like India. Objective: To ascertain measles immunization coverage, factors leading to drop-outs and parents' knowledge, attitude and perceived practices on it. Materials and Methods: A community based cross-sectional study design was adopted to study the children's dropout in measles immunization. 210 children aged between 12 and 23 months in Kanyakumari district had been picked up from the entire population of 182519 using $30 \times 7$ cluster random sampling. Results: The study has shed some light on the coverage of measles vaccination of $81.4 \%$ with dropout of $18.6 \%$. There were no statistically significant associations between area of residence, place of birth, sex, parental marital status, mothers' pregnancy status \& availability of immunization card and dropouts. In regards to their parents' knowledge, attitude and perceived practices on Measles, 93.3\% had vast awareness. Conclusion: A few factors like ignorance, long gap between administration of two vaccinations, lack of awareness on adverse impact of Measles, have hampered the program from reaching all children in the district. However, these challenges might be addressed through increasing the level of awareness among the parents, identification of dropout cases, scaling up of vaccination programs at gross root level, etc.

Keywords: Dropout, Measles, Mortality, Morbidity, Under-five Children

\section{Corresponding Author}

Anantha Raman V. V., MD, Associate Professor, Department of Community Medicine, SRM Medical College and Research Centre, Kanchipuram, Tamil Nadu, India.

Email: drvaraman@yahoo.co.in

\section{How to Cite this Article}

Mathiarasu AM, Raman VVA, Mathew AM. Prevalence of dropout in measles immunization coverage among children in Kanyakumari District, Tamilnadu. Public Health Rev Int J Public Health Res. 2017;4(1):26-30. Available From https://publichealth.medresearch.in/index.php/ijphr/ article/view/57
To Browse

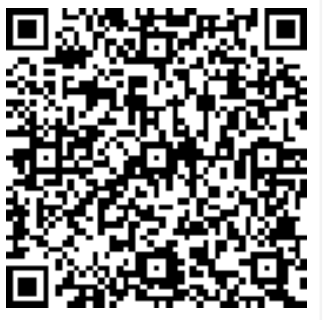

Manuscript Received 2017-02-06

Conflict of Interest No
Review Round 1 2017-02-14

Funding

Review Round 2
2017-02-21
Ethical Approval
Yes

Review Round 2

Yes
Review Round 3

Accepted 2017-02-28

Plagiarism X-checker $7 \%$

(c) 2017 by Alber M. Mathiarasu, Anantha Raman V. V., Arumai M. Mathew and Published by Siddharth Health Research and Social Welfare Society. This is an Open Access article licensed under a Creative Commons Attribution 4.0 International License https://creativecommons.org/licenses/by/4.0/ unported [CC BY 4.0]. 


\section{Introduction}

Measles is highly prevalent across globe and it is the main cause for childhood mortality and morbidity. It has now come down in developed countries that favour interruption of transmission [1]. Nevertheless, it is still continuing as widespread disease in developing countries like India. The mortality rate increasingly crosses $95 \%$ in many parts of the globe, where people have less access to health care system and live below poverty line.

It is fairly very high as compared to the developed countries that have prevalence rate of $1 / 1000$. Approximately $1,22,000$ children under the age of five years died of measles in 2012 globally. In India measles had 84 outbreaks in 2014 leading to 5,248 cases. According to World Health Organization (WHO) estimates, measles is responsible for about $4 \%$ of under-five children's mortality in India [2].

Epidemiological determinants of measles satisfy the criteria for eradication. Still WHO aims to achieve measles elimination only by 2020 and they have not fixed any date for eradication. It is because the mathematical models in developing countries suggest that the average case of measles may result in transmission to 12 to 18 persons in a totally susceptible population. Thus, it is estimated that the $94 \%$ or higher the immunity level needed to interrupt transmission [3].

The age specific level of immunity needed to prevent transmission has been affected by substantial variation in contact rates by age groups. Absolute cessation of transmission is possible only with $100 \%$ of the target population attaining immunity to the disease. However in measles, the population immunity of $80 \%$ only can be achieved by this vaccine's efficacy of $85 \%$ and the actual $95 \%$ coverage.

Thus in measles, the said immunity is still a long way off [4]. Epidemiology of measles is of related to population size, density, over-crowding, movement and social behavior. The effects of measles infection predisposes to health problems in later life too. Even though measles immunization was introduced in India as part of UIP from 1985, the coverage achieved in different geographical areas is highly variable.

The most worrying part in India is that the vaccination coverage against measles is only $66 \%$ and even below $50 \%$ in some states, even for the first dose of vaccine [5].
According to DLHS-3 in 2004-2008, the national routine measles vaccination coverage was $69 \%$ in Kayakumari District, measles coverage was only $78.2 \%$ in 2008, in spite of high literacy [6]. According to NFHS-3 in 2005-2006, in Tamilnadu, the measles immunization coverage was $60 \%$ [6]. But the immunization coverage of Tamilnadu obtained from a Non-governmental organization Makkal Nalavazhvu Iyyakam, Christian Medical College, Vellore is $87.6 \%$ and it reflects the true scenario in the state at the field level [7].

In Tamilnadu, although the State Health Mission Department has been claiming $>90$ immunization coverage, studies by organizations including UNICEF have shown a $20 \%$ drop in measles immunization coverage in the state since 2008. This drop in immunization coverage was due to various factors including the impact of death of four children at Tiruvallur district near Chennai in 2008 due to adverse effects, following immunization (AEFI) by measles vaccination.

Due to this, from the year 2009 the place of immunization has been changed from door steps to primary health centers. Again the measles vaccination was carried out in field since 2012. WHO targets measles, next to polio for eradication. The output of the measles immunization program is measured in terms of vaccination coverage and dropout rates. As vaccination coverage measures access to immunization services, dropout rates indicates service utilization [8].

However, still there have been wide gaps existing among people in utilizing measles vaccination services of health care centers in Kanyakumari district. In order to identify these gaps and facilitate the program managers and administrators working in the field of health to devise an appropriate change to improve measles immunization coverage, an empirical research study has been carried out in Kanyakumari District.

\section{Objectives}

To ascertain measles immunization coverage, various factors leading to drop outs and parents' knowledge, attitude and perceived practices on it.

\section{Materials and Methods}

A community based cross-sectional study design was adopted to study the children's dropout in measles immunization. 
It was executed between June-2012 and May-2013 covering 267 rural health centers and 36 urban centers in Kanyakumari district. 210 children aged between 12 and 23 months had been selected from the entire population of 182519 using $30 \times 7$ cluster random sampling. Initially, the population was divided into 30 clusters with the cluster interval of 60857 people each.

Subsequently, the random number 17515, which was lesser than the population size of a cluster interval, has been selected using simple random sampling method. Each cluster had 3 to 10 RHCs and UHCs alternately. The cumulative population of RHCs and UHCs, in which the random number 17515 falls, was considered a first cluster.

The second cluster was selected by adding the cluster interval population size of 60857 to the random number 17515 and cumulative population where it was fallen. The same procedure continued until 30 clusters were selected from the entire population covering all RHCs and UHCs. A semistructured and pretested questionnaire was administered to obtain data from the children's parents and guardians.

It had three domains such as 1 . Socio-economic and demographic profile, 2 . Their knowledge attitude and perceived practice on measles immunization 3 . Various causes for not immunizing against measles. The data collected were collated, edited, codified and entered into computer using SPSS software.

Subsequently, they were tabled, analyzed and interpreted according to its study objectives. Statistical tests like Chi-square, Test of Significance and Multiple Regressions were simultaneously used to determine the association between immunization and other factors leading to their drop out.

\section{Results}

The study population included 210 children aged between 12 and 23 months, of whom $59.1 \%$ were in the age group of $18-20$ months. The Mean age was 18.1 with the standard deviation of 3.1 months. As for gender, the female children constituted $52 \%$, which was slightly higher than the male children of $48 \% .83 .3 \%$ were residents of rural areas. Religion wise, $52.8 \%$ have professed Christianity, whereas only $40.5 \%$ belonged to Hinduism.

The type of families they lived in showed that $53.8 \%$ were part of nuclear family and $37.6 \%$ were part of three generation family.
With regard to their order of birth, $51.9 \%$ stood at second order, while $46.7 \%$ were at first order. According to the classification of modified Kuppusamy SES scale, their socio-economic status has been shown in the Table- 1 In respect of marital life, $96.7 \%$ of the parents were leading legitimate marital lives. The status of administration of vaccine against Measle is apparently shown in the Figure-1

As regards possession of immunization card, age and time of vaccination, $84.8 \%$ of the children's parents had cards showing various vaccinations administered to their children. $81.4 \%$ of them, who have been vaccinated against Measles, availed it minimum at their 278th days and maximum at their 358th days. The mean age of the vaccination was 293.94 days with the standard deviation of 26.012 days.

$61.4 \%$ of the parents had utilized the services of government hospitals including PHCs and HSCs for their children's vaccination, but only $35.1 \%$ had utilized the services of private hospitals for it. $58.5 \%$ of the parents have accompanied their children during the vaccination. In regard to factors associated with non-immunization, the below diagram gives nugget of information on them...Chisquare test was applied to find the association between the demographic factors and drop outs.

The upshot showed that there were no statistically significant associations between area of residence, place of birth, sex, parental marital status, mothers' pregnancy status $\&$ availability of immunization card and drop out. Similarly, multiple regression analysis was applied to find out association between demographic factors and drop out. It was found that no such statistical significant associations were found between them.

With respect to religion \& dropout and socioeconomic status \& drop out, $25.2 \%$ of the children professing Christianity and $11.8 \%$ of them professing Hinduism not got immunized. Likewise, $16.7 \%$ of the children from upper middle class and $18.1 \%$ from lower middle class were not administered vaccination against Measles.

$93.3 \%$ of children's parents were aware of Measles, of whom $39.8 \%$ gained knowledge through their relatives and $33.7 \%$ through their neighbours, $64.8 \%$ knew Measles is preventable disease, and $74.5 \%$ knew it should be administered at 9th month.

Figure-1: Immunization Status 


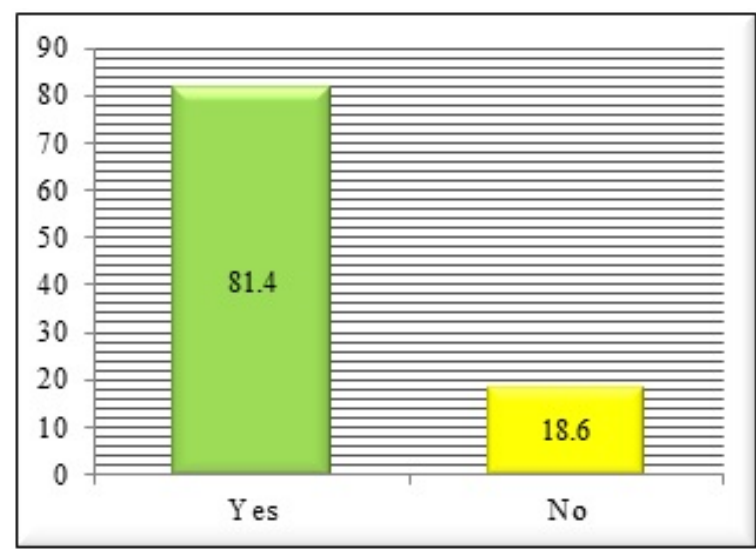

Table-1: Socio-Economic Status and Non Immunization

\begin{tabular}{|l|l|l|l|}
\hline \multirow{2}{*}{ Class } & \multicolumn{2}{|c|}{ Non Immunization } & \multirow{2}{*}{ Total } \\
\cline { 2 - 3 } & Yes & No & \\
\hline Upper & $1(14.3 \%)$ & $6(85.7 \%)$ & $7(100 \%)$ \\
\hline Upper Middle & $16(16.7 \%)$ & $80(83.3 \%)$ & $96(100 \%)$ \\
\hline Lower Middle & $13(18.1 \%)$ & $59(81.9 \%)$ & $72(100 \%)$ \\
\hline Upper Lower & $9(25.7 \%)$ & $26(74.3 \%)$ & $35(100 \%)$ \\
\hline Total & $39(18.6 \%)$ & $171(81.4 \%)$ & $210(100 \%)$ \\
\hline
\end{tabular}

Table-2: Reason for Dropouts

\begin{tabular}{|l|l|}
\hline \multicolumn{1}{|c|}{ Reason } & Number \\
\hline Lack of Transportation & 2 \\
\hline Ignorance & 5 \\
\hline Long gap between two vaccination & 10 \\
\hline Already infected with Measles & 4 \\
\hline Fear of adverse impact & 4 \\
\hline Sickness at the time of vaccination & 4 \\
\hline Inconvenient date and time & 1 \\
\hline Not aware of vaccination schedule & 7 \\
\hline Time and place not known & 2 \\
\hline
\end{tabular}

\section{Discussion}

Routine immunization is the foundation for achieving and sustaining measles elimination and Rubella control. The challenges that must be overcome are significant and are in various stages of being addressed. Grass root level challenges in vaccination coverage have to be identified and rectified to make $100 \%$ coverage which is the major step for elimination of measles in India.

This would facilitate the policy makers and other stakeholders in service sectors to overcome issues of dropouts in immunization coverage. The present study shows that $81.4 \%$ of the children aged between 12-23 years in Kanyakumari district have been immunized for Measles with $18.6 \%$ dropouts, but, other studies show the Measles immunization
Coverage was $87.1 \%$ with $12.9 \%$ dropouts, which was slightly higher than the current study [9]. However, it is slightly higher than the national immunization evaluation study done by UNICEF in 2009 with $80 \%$ immunization coverage for Measles [10].

Of the vast majority of the children immunized against Measles, $64.9 \%$ of the parents had chosen government hospitals to vaccinate their children and $35.1 \%$ of them chose private clinics to do so. It significantly correlates with Niyiawofeso et al study [11], where over three-fifth the parents opted to vaccinate their children in government hospitals. As for the factors associated with non immunization of children, $25.6 \%$ of the parents informed that forgetfulness was the common reason. However, $17.9 \%$ of the parents felt it was due to ignorance.

A similar study conducted in Surat city [12] wherein $12.9 \%$ of the parents stated that it was their ignorance due to which Measles vaccination was not administered to their children. There were statistically significant associations between factors like ignorance, fear of adverse impact and lack of information on place and time of immunization and drop outs in the present study and the study of Yadav et al [13].

Regarding dropout in relation to gender, female children were more likely to be dropout than male children, which was closely correlated with a study conducted by Rashmi Sharma et al [14]. On socioeconomic status of children, according to Kuppusamy Scale, it was observed that the children belonged to low SES had higher dropout. However, there was no statistical significant association between SES and dropouts.

With regard to their parents' knowledge, attitude and perceived practices on Measles, $93.3 \%$ had vast awareness, of whom, $39.8 \%$ gained it through their relatives and $33.7 \%$ through neighbours. In contrast, the other study carried out at Brigham University in US, [15] it was indicated that majority of the parents whose children had been immunized for Measles, gained knowledge through health care providers. It was evident that people living in rural setup had good knowledge about measles.

\section{Conclusion}

The study has shed some light on the wider coverage of measles vaccination of $81.4 \%$ with dropout of $18.6 \%$ in Kanyakumari district. 
A few factors like ignorance, long gap between administration of two vaccinations, lack of awareness on adverse impact of Measles and place and time, have hampered the program from reaching all children in the district.

However, these challenges might be addressed through increasing level of awareness among the parents through behaviour change communication by nurses, awareness programs through media at regular interval, initiation of field level monitoring by sector health nurses, maintaining close contact with children by providing iron or vitamin syrup monthly during the gap between 3rd dose of DPT and measles, identification of dropout cases through village health nurses, scaling up of vaccination programs at grass root level through mobile camps, and carrying out more research programs on measles.

\section{Reference}

01. United National International Children's Fund (UNICEF). Partners in Global Initiative- Global goal to reduce measles deaths in children surpassed. 2007.

Available at: [Article] [Crossref]

02. Government of India. Diseases alert/outbreaks reported and responded to be States/UTS through integrated disease surveillance programme(IDSP). New Delhi- National Health and Rural Health Mission-Ministry of Health and Family Welfare. 2014; Jan. Available from:

[Article] [Crossref]

03. Walter A, Orenstein, Papania M, Strebel P. Vaccine preventable diseases-Measles. USAMcGraw-Hill Medical Publisher. 2008.

[Crossref]

04. Poland GA, Jacobson RM. The re-emergence of measles in developed countries- Time to develop the next-generation Measles vaccines?. Vaccine. 2012 Jan-5;30(2)103-104.

doi: $10.1016 /$ j.vaccine.2011.11.085 [Crossref]

05. Health FAQs-Measles. 2016. Available at: [Article] [Crossref]

06. International Institute of Population Studies (IIPS). District level household and facility survey (DLHS-3) 2007-08. 2010.

Available at: [Article] [Crossref]
07. International Institute of Population Studies (IIPS). National family health survey (NFHS-3) 2005-06. 2007.

Available at: [Article] [Crossref]

08. Kishore J. Reproductive and child health program-II, In J K, National Health Programs of India. New Delhi- Century Publishers. 2011.

[Crossref]

09. Pushpa N. TN moms to get cash for vaccines. The Times of India (Chennai) [Serial online]. 2011 Aug 11; Sect. News- A14.

Available from: [Article] [Crossref]

10. United Nation Children's Fund (UNICEF). Coverage Evaluation Survey 2009 - National Fact Sheet. 2009.

Available from: [Article] [Crossref]

11. Awofeso N, Rammohan A, Iqbal K. Ageappropriate vaccination against measles and DPT-3 in India - closing the gaps. BMC Public Health. 2013;Apr-17;13;358.

doi: 10.1186/1471-2458-13-358 [Crossref]

12. Desai VK, SJ Kapadia, Kumar P, Nirupam S. A study of Measles incidence and vaccination coverage in Slums of Surat City. Indian Journal of Community Medicine. 2003; Jan 1; 28(1)1014.

[Crossref]

13. Singh $P$, Yadav RJ. Immunization status of children of India. Indian Pediatrics. 2000;Nov;37(11)1194-9.

[Crossref]

14. Sharma R, Desai VK, Kavishvar A. Assessment of immunization status in the slums of Surat by 15 clusters multi indicators cluster survey technique. Indian Journal of Community Medicine. 2009 Jan 4;34(2)152-155. doi: 10.4103/0970-0218.51222 [Crossref]

15. Luthy KE, Beckstrand RL, Peterson NE. Parental hesitation as a factor in delayed childhood immunization. J Pediatr Health Care. 2009 NovDec;23(6)388-93.

doi: 10.1016/j.pedhc.2008.09.006 [Crossref] 